\title{
Protease and antiprotease levels in blood of arthritic rats
}

\author{
D. P. PARROTT AND D. A. LEWIS
}

From the Pharmacological Laboratories, Department of Pharmacy, University of Aston, Birmingham B4 7 EM

SUMMARY Protease, antiprotease, and acid phosphatase blood levels of adjuvant arthritic rats wewe determined. The protease levels appear to vary inversely with the antiprotease levels. Changes in the protease levels correspond closely to changes in the acid phosphatase levels. Thus it is likely that the lysosomes contribute to the proteases present in the blood. Administered cortisol appears to raise blood antiprotease levels in both normal and arthritic rats and this may reflect an anti-inflammatoony action by this drug.

Recently interest has been focused on the role of antiproteases in inflammatory disease. In particular, serum and synovial fluid levels of alpha ${ }_{1}$-antitrypsin and other antiproteases have been found to rise in patients with rheumatic disease (Brackertz et al., 1975). The most abundant antiprotease in plasma is alpha $_{1}$-antitrypsin (Kueppers, 1971) and this protein has a broad specificity against proteases including many believed to be involved in inflammatory processes (Hercz, 1974).

Protease action has been implicated at several levels in joint inflammation. In the acute inflammatory stage kallikrein activity results in the formation of bradykinin and possibly other kinins found in rheumatoid synovial fluid. In the later stages of joint disease the destruction of cartilage is undoubtedly due to the proteolytic degradation of its two major extracellular components, collagen and proteoglycans. At least two collagenases, one of lysosomal origin isolated from leucocytes (Lazarus et al., 1968) and a synovial collagenase (Harris et al., 1970), are capable of degrading joint collagen and leucocytes also contain a neutral protease (Weissman and Spilberg, 1968) which is capable of degrading proteoglycans, cartilage matrix, and histones. Dingle (1962) produced evidence that lysosomal proteases, particularly cathepsin $D$, are responsible for the initial breakdown of the cartilage matrix. It may then be argued that any interaction between plasma antiproteases and proteases involved in inflammatory processes may well be anti-inflammatory in nature.

Accepted for publication July 8, 1976 Correspondence to Dr. D. A. Lewis
The experiments reported in this paper were do (1) to investigate the blood levels of proteases amd antiproteases simultaneously in rats with induced adjuvant polyarthritis; (2) to investigate the effeet of administered steroid on blood alpha -antitrypsin $_{1}$ levels; (3) to investigate the protease activity and the acid phosphatase activity in the granulation tissaie and oedema fluid of the joints of rats with induced adjuvant polyarthritis.

\section{Materials and methods}

INDUCTION AND ESTIMATION OF

ADJUVANT ARTHRITIS

Freund's adjuvant $(0.05 \mathrm{ml})$ was injected into the footpads of the left hind feet of male Wistar rats (200 $\mathrm{g}$ approx). The adjuvant consisted of humin strains of C, DT, and $\mathrm{N}$ heat-killed tubercle baci (kindly supplied by the Ministry of Agricultuge Veterinary Laboratories, Weybridge, Surrey) suspended in liquid paraffin $(5 \mathrm{mg} / \mathrm{ml})$, as previous described (Pearson and Wood, 1959).

The inflammatory response to the adjuvant was measured in both hind feet by immersing the separately up to the hair line in a mercury bath connected to a pressure transducer, linked to ga Devices recorder. The initial measurements of foet volume were taken before injection of the adjuvant and subsequent measurements made during the experiment.

\section{CORTISOL TREATMENT}

A group of normal rats and a group of the raps injected with Freund's adjuvant were given from day 0 , daily throughout the duration of the experi- 
ment, subcutaneous injections of cortisol acetate suspension $(5 \mathrm{mg} / \mathrm{kg}$ body weight) in saline $(0.9 \%)$. The noncortisol-treated rats were given equivalent injections of saline $(0.9 \%)$ alone, following the above procedure.

\section{SAMPLE COLLECTION}

Blood samples were obtained by cardiac puncture: after separation the serum was stored at $-20^{\circ}$. At the end of the experiment an examination of the joints of the arthritic rats showed that they were a mass of calcified granulation tissue honeycombed with small spaces filled with a clear colourless fluid. This oedema fluid was squeezed out in a tissue mincer from which the cutter had been removed. The residual tissue was extracted with cold saline. It was not possible to remove synovial fluid from normal rat joints so the corresponding amount of joint tissue was minced and extracted with cold saline. Both the oedema fluid and the saline extracts were stored at $-20^{\circ}$.

\section{ENZYME DETERMINATIONS \\ Protease levels}

These were determined on serum and tissue fluids and tissue extracts as previously described (Rinderknecht et al., 1968). Hide powder Azure Blue was used as the substrate (Calbiochem) and the amount of dye released from the substrate was determined at $595 \mathrm{~nm}$. The amount of substrate digested was equated to the amount of dye released by control experiments using trypsin as the digesting enzyme. Enzyme activity was determined at $\mathrm{pH} 7 \cdot 4$.

\section{Acid phosphatase activity}

The activity in serum, tissue fluids, and tissue extracts was determined as described previously (Symons et al., 1969) using p-nitrophenyl phosphate as the substrate.

\section{Antiprotease determinations}

The trypsin inhibiting capacity of serum was measured as previously described (Dietz et al., 1974) by the inhibiting action of the serum on the breakdown of $\alpha$-N-benzoyl-DL-arginine-p-nitroanilide (BAPNA) by trypsin.

\section{HISTOLOGY}

Granulation tissue was removed and fixed in gum (Ames OCT compound) by freezing with carbon dioxide. Sections $(10 \mu \mathrm{m})$ were cut using a freezing cryostat (Bright's Teddington Q.R.) and the proteolytic activity located by mounting the section on exposed and developed photographic film. The section was incubated under moist conditions at $37^{\circ}$ for various periods of time, determined by pre- liminary experiments, and the film well washed in distilled water. The film was then examined by the light microscope. Where the gelatin film had been dissolved by proteases in the section the silver granules were removed by the washing procedure leaving an imprint of tissues rich in proteases. The method has been described by Adams and Tuquan (1961).

\section{Results}

\section{ADJUVANT ARTHRITIS IN THE RAT}

The foot volumes measured during the experiment are plotted in Fig. 1 as the increase in volume over the values obtained immediately before injection of the adjuvant. The figure shows that cortisol has an anti-inflammatory action on both the initial and later phases of inflammation.

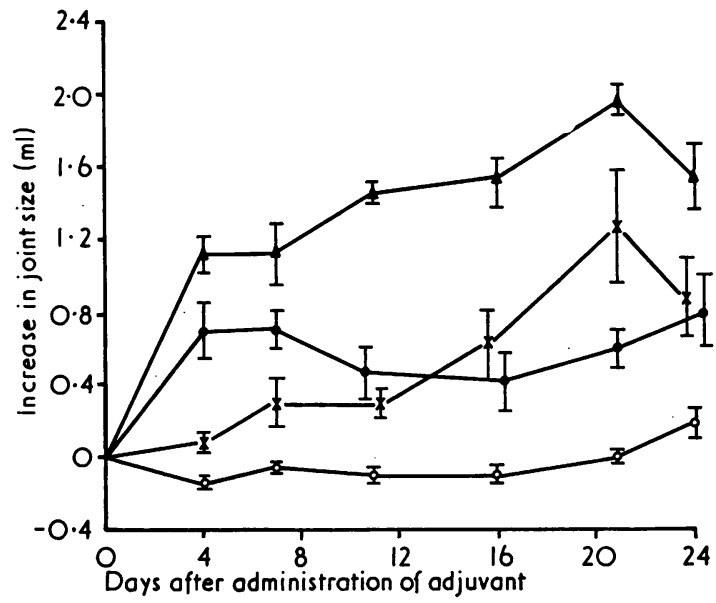

Fig. 1 Increase in size of left $(\mathbf{A})$ and right $(\mathrm{x})$ hind feet of rats after injection of mycobacterial adjuvant. Increase in size of left $(\bullet)$ and right (0) hind feet of rats treated daily with cortisol acetate suspension $(5 \mathrm{mg} / \mathrm{ml}$ ) after injection of mycobacterial adjuvant. Each result represents the mean $\pm S E M$ of 5 animals.

\section{PROTEASE AND PHOSPHATASE ACTIVITY} IN SERUM

The protease activity against the collagen substrate used in the assay was very small for normal serum (about $0.5 \mathrm{mg}$ substrate broken down per $\mathrm{ml}$ serum in $24 \mathrm{~h}$ ) but increased significantly during inflammation. This increase over normal values is plotted in Fig. 2. Raised protease levels accompany both the initial acute inflammatory stage and the later chronic inflammatory stage. Fig. 2 also shows the acid phosphatase levels which follow the same pattern as the protease levels. Since acid phosphatase 
is a lysosomal marker it may well be that a contribution to the raised protease levels was made by lysosomes.

\section{ANTIPROTEASE LEVELS IN SERUM}

The trypsin inhibiting capacity (TIC) values are plotted in Fig. 3. Clearly these were depressed during the course of adjuvant-induced arthritis and the

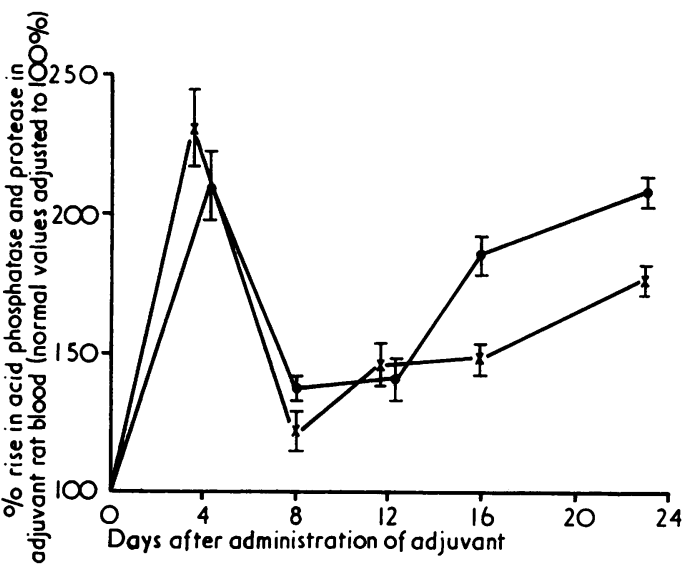

Fig. 2 Variation of blood acid phosphatase (0) and protease $(\mathrm{x})$ levels compared with normal levels (adjusted to $100 \%$ for each sample) on various days after administration of adjuvant. Each result represents the mean $\pm S E M$ of 5 animals.

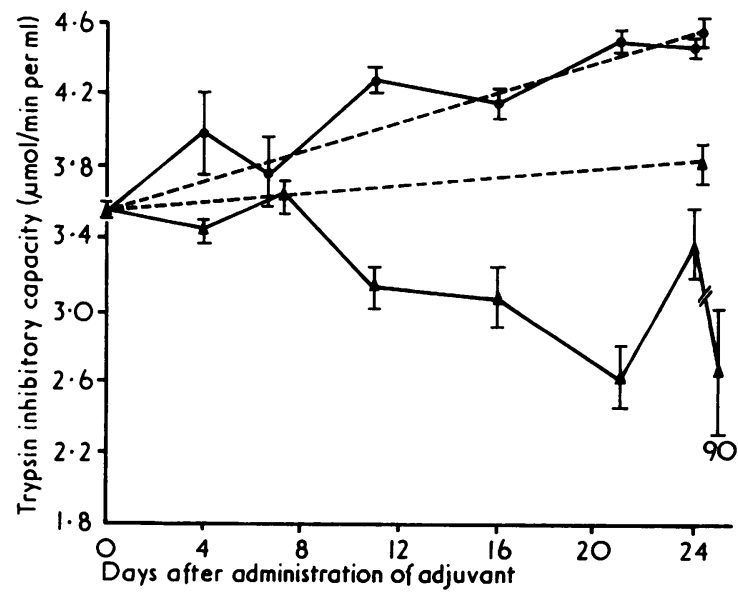

Fig. 3 Variation of the trypsin inhibitory capacity of serum in adjuvant arthritic rats $(\mathbf{A})$ and adjuvant arthritic rats treated daily with cortisol acetate suspension $(5 \mathrm{mg} / \mathrm{ml})$ (๑). Broken lines represent nonarthritic rats. Each result represents the mean $\pm S E M$ of 5 animals. levels are inversely related to the protease levets plotted in Fig. 1. The TIC levels were depressêd during the acute inflammatory stage when the pr $\vec{f}$ tease levels were raised and they also fell during the development of chronic inflammation when the protease levels again rose.

Clearly the daily administration of cortise acetate not only had an anti-inflammatory effeett (Fig. 1), but also stimulated antiprotease levels in thre blood (Fig. 3). Since the cortisol acetate treatme also stimulated the TIC levels in normal rat serum the stimulating action may be due to the steroid arfo not necessarily to any agent produced during inflammation. Although serial protease determin $\vec{\not}$ tions were not carried out on serum samples takey from the cortisol-treated rats with adjuvant-induced arthritis, spot checks on some of the samples showed that the protease levels in these samples were on slightly above normal.

Table Comparison of the protease and acid phosphatase levels in the oedema fluid and tissue of the joints of normal and arthritic rats

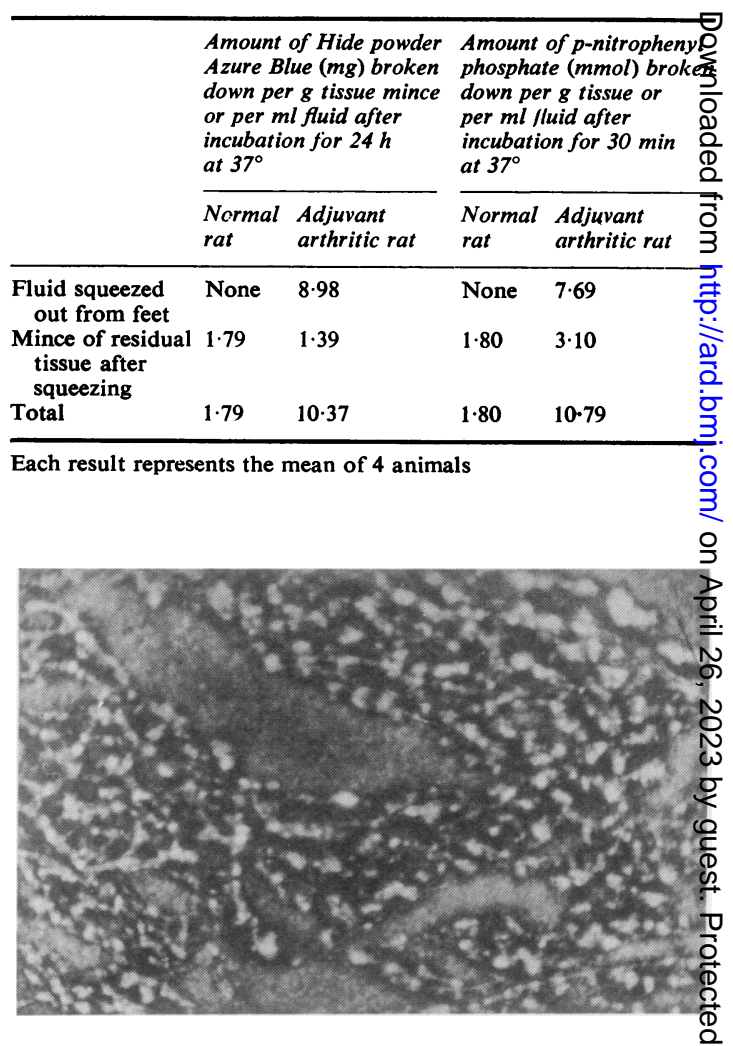

Fig. 4 Protease-rich granulation tissue from polyarthrit rat feet. $\times 245$. 
PROTEASE AND ACID PHOSPHATASE LEVELS IN ADJUVANT ARTHRITIC RAT FEET

These values are given in the Table. The acid phosphatase values are in agreement with those of Anderson (1970) who suggested that the raised acid phosphatase levels showed the involvement of lysosomes in the development of the arthritis. The protease levels are also higher in the arthritic feet and an examination of sections taken from the arthritic joints show that the granulation tissue is enriched with proteases active against gelatin (Fig. 4).

\section{Discussion}

The elevation of proteases and the depression of antiproteases in the serum of rats with adjuvantinduced arthritis suggests an association between

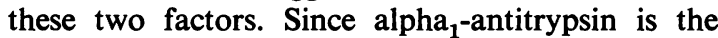
most abundant antiprotease in plasma and the assay system used is designed to measure alpha ${ }_{1}$-antitrypsin levels it seems likely that the variation in antiprotease levels reported are primarily due to alpha ${ }_{1}$ antitrypsin. The fluctuations in the protease levels in the serum of rats with adjuvant-induced disease are of interest since they follow the same pattern as the acid phosphatase levels, and acid phosphatase is regarded as a lysosomal marker. We have previously reported the variations in acid phosphatase levels in the blood of adjuvant arthritic rats (Collins and Lewis, 1971), and Persellin (1972) has suggested that the initial rise in acid phosphatase levels is due to liver damage which occurs shortly after the administration of the adjuvant. It may well be that the rise in the protease levels associated with the acute inflammatory action of the adjuvant may be a consequence of this liver damage since Persellin (1972) claims that the damage to liver lysosomes is lessened by the production of an $\alpha$-globulin which can stabilize liver lysosomes. It may be that the leakage of proteases from the inflamed joints into the circulation is responsible for the raised protease levels found in the chronic inflammatory stage. Clearly the raised levels of protease in the fluids and tissue minces of the arthritic joints are consistent with this suggestion and the histology has shown that the granulation tissue is enriched with proteases.

In humans the serum and synovial fluid levels of alpha ${ }_{1}$-antitrypsin, assayed by immunochemical techniques, rise in rheumatic disease. In the adjuvant arthritic rats the trypsin inhibitory capacity fell in animals that were not treated with steroid. Although these findings may reflect a species difference it is also possible that the formation of protease-antiprotease complexes, due to high blood protease levels, were responsible for the depression of antiprotease activity in this case. The inactive antipro- teases present in such complexes would not be detected by our enzymatic assay but only by immunochemical techniques (Brackertz et al., 1975). The stimulating action of cortisol on the trypsin inhibitory capacity of serum in both normal and adjuvant arthritic rats is of interest for if antiproteases do have an anti-inflammatory action in vivo then the stimulating action of cortisol on endogenous antiprotease levels may well represent another method by which cortisol exerts its antiinflammatory action in rheumatoid diseases.

We thank the Arthritis and Rheumatism Council for financial support and Miss Susan Eccles for assistance with the histology.

\section{References}

Adams, C. W. M., and Tuquan, N. A. (1961). The histochemical demonstration of protease by a gelatin-silver film substrate. Journal of Histochemistry and Cytochemistry, 9, 469-472.

Anderson, A. J. (1970). Lysosomal enzyme activity in rats with adjuvant-induced arthritis. Annals of the Rheumatic Diseases, 29, 307-313.

Brackertz, D., Hagmann, J., and Kueppers, F. (1975). Proteinase inhibitors in rheumatoid arthritis. Annals of the Rheumatic Diseases, 34, 225-230.

Collins, A. J., and Lewis, D. A. (1971). Lysosomal enzyme levels in the blood of arthritic rats. Biochemical Pharmacology, 20, 251-253.

Dietz, A. A., Rubenstein, H. M., and Hodges, L. (1974). Measurement of alpha ${ }_{1}$-antitrypsin in serum by immunodiffusion and by enzymatic assay. Clinical Chemistry, 20, 396-399.

Dingle, J. T. (1962). Aetiological factors in the collagen diseases. Lysosomal enzymes and the degradation of cartilage matrix. Proceedings of the Royal Society of Medicine, 55, 109-111.

Harris, E. D., Evanson, J. M., Di Bona, D. R., and Krane, S. M. (1970). Collagenase and rheumatoid arthritis. Arthritis and Rheumatism, 13, 83-93.

Hercz, A. (1974). The inhibition of proteinases by human alpha ${ }_{1}$-antitrypsin. European Journal of Biochemistry, 49, 287-292.

Kueppers, F. (1971). Alpha ${ }_{1}$-antitrypsin: physiology, genetics, and pathology. Humangenetik, 11, 177-189.

Lazarus, G. S., Daniels, J. R., Brown, R. S., Bladen, H. A., and Fullmer, H. M. (1968). Degradation of collagen by a human granulocyte collagenolytic system. Journal of Clinical Investigation, 47, 2622-2629.

Pearson, C. M., and Wood, F. D. (1959). Studies of polyarthritis and other lesions induced in rats by injection of mycobacterial adjuvant, 1. General clinical and pathological characteristics and some modifying factors. Arthritis and Rheumatism, 2, 440-459.

Persellin, R. H. (1972). Lysosome stabilization by adjuvant arthritis serum. Arthritis and Rheumatism, 15, 144-152.

Rinderknecht, H., Geokas, M. C., Silverman, P., Lillard, Y., and Haverback, B. J. (1968). New methods for the determination of elastase. Clinica Chimica Acta, 19, 327-339.

Symons, A. M., Lewis, D. A., and Ancill, R. J. (1969). Stabilising action of anti-infiammatory steroids on lysosomes. Biochemical Pharmacology, 18, 2581-2582.

Weissman, G., and Spilberg, I. (1968). Breakdown of cartilage protein polysaccharide by lysosomes. Arthritis and Rheumatism, 11, 162-169. 